\title{
The application of DTM method in the earthwork calculation by partition
}

\author{
Yijie Wang ${ }^{1}$ Hao Zhang ${ }^{2}$ \\ ${ }^{1}$ College of Civil Engineering and Architecture, Zhejiang University of Technology, Hangzhou \\ 310032, China \\ ${ }^{2}$ College of Civil Engineering and Architecture, Zhejiang University of Technology, Hangzhou \\ 310032, China
}

KEYWORD: earthwork calculation, the partition to the measurement area, the DTM method, the Southern Cass9.1 software

ABSTRACT: no matter which method chosen to calculate earthwork, it always needs to consider about describing the design surface as accurate as possible. However, in fact, each project has different construction from each other. And each construction has its different design elevation. Meanwhile, for a complete project, the distribution of the supporting facilities, like accessory equipment, internal road and landscape, are also needed to be considered. In such case, it will cost a large amount of time and energy to accurately describe the design surface. Therefore, this paper combines with the earthwork calculation of the actual project, on the premise of meeting the requirements of engineering design, and provides a relatively accurate, rapid and simple way to calculate the earthwork quantity of the measurement area by using the DTM method of the Southern Cass 9.1 software and do some effective partitions to the measurement area.

\section{Introduction}

The accuracy of earthwork calculation depends on the precise degree of the description to upper and lower surface in the actual measurement range. The upper surface is the real terrain of the measurement range, whose accuracy depends on the distribution and the intensive degree of the collecting data points. While the lower surface means the complex design terrain, it varies from each project. Theoretically speaking, DEM (Digital Elevation Model) can be created to describe the design surface entirely and accurately by software or manual input with the coordinates and elevation of the design points. Whereas, from the perspective of practical project, the method of creating DEM is inoperable on account that it's a time-consuming work and it exists unpredictable personal error and accumulative error . As a result, this paper provides a method of improvement, which is not only relatively accurate to describe the complex design terrain surface, but also could reduce the accumulative error by some reasonable partitions to the measurement area.

\section{General measurement area situation}

The length of the measurement area in the $\mathrm{x}$ direction is $167 \mathrm{~m}$, and in the y direction is $212 \mathrm{~m}$ within the property line on the architectural design drawing(on the Fig. 1, it's same to the below that $\mathrm{X}$-axis is the vertical direction and $\mathrm{Y}$-axis is the transverse direction). 


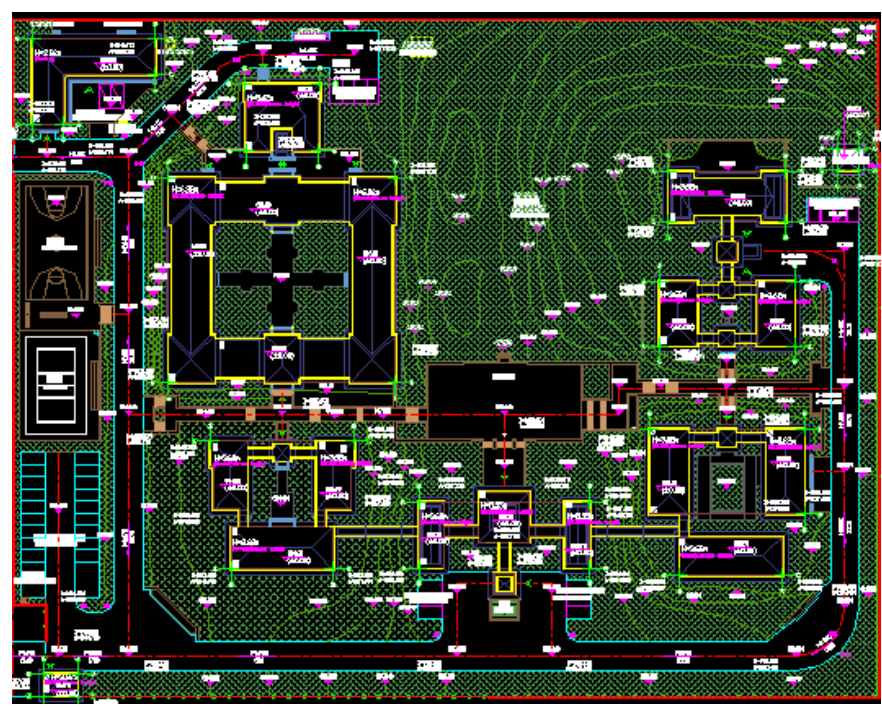

Fig.1 Architectural design drawing

The measurement area has a variety of constructions, such as buildings, basketball court, landscape hill, equipment, road and so on. As shown on the Fig.1 that each one has a different elevation. What's more, there is a gradient for the road and landscape hill. Meanwhile, each architectural design area is not a regular graphics. Therefore it's a really hard work to describe the design terrain surface completely and accurately. Based on the distribution of the measured data points shown on the Fig.2, which are intensively distributed in the surrounding and the middle area is relatively small in uniform distribution, it comes to the point that this distribution suits DTM method to calculate the earth volume by G. Feng etc.

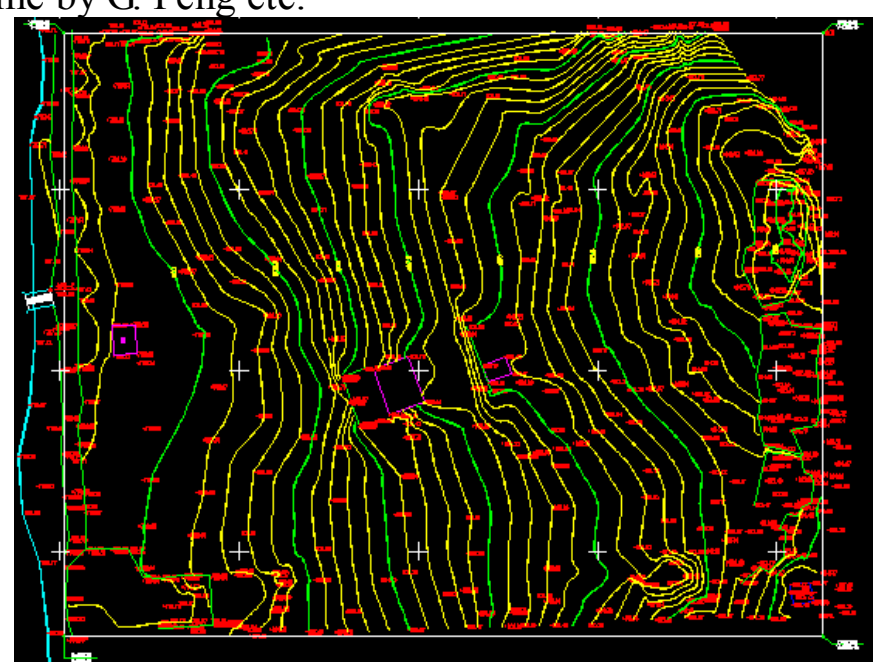

Fig.2 Measurement topographic map

The DTM method uses the irregular triangle net to connect the data points covering the whole area, calculating the earth volume by triangular prism method. This method requires more data points to appropriately distribute on the boundary. Because those feature points and the known points are relatively easy to test distribution on the border. It can reduce the accumulative error obviously. So for the general measurement area situation, it is the DTM method that should be chosen to calculate earth volume.

\section{Earthwork calculation}

\section{Dividing the calculation area.}

Carefully compared the distribution of the buildings' design elevation on the Fig. 1 with each segment's design elevation on Fig. 3 and Fig.4, it can be seen that the design elevation of the whole design area is roughly four ladder-like distribution. 

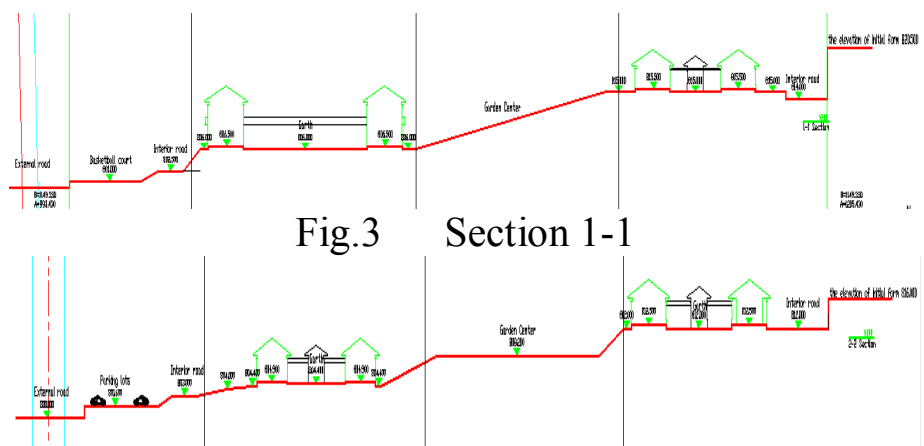

Fig.4 Section 2-2

According to the demands of earthwork calculation is to meet the corresponding to the bottom of the building's elevation in the practical project as far as possible, avoiding digging in rework, and calculating the dig-fill earthwork quantity as accurately as possible, therefore, the calculation area should be divided into 1, 2, 3, 4, 5 from left to right, a total of five areas. As shown in Fig.5.

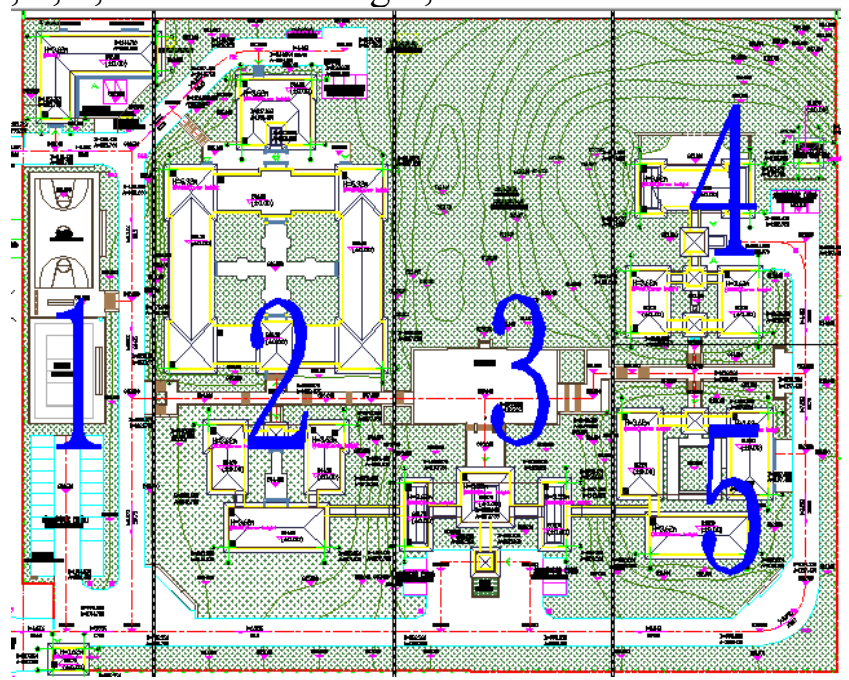

Fig.5 Calculating zoning map

\section{Calculating the computing bottom elevation of each area}

Analyzing the distribution of the architectural design elevation in each area, on the premise of the accuracy, the plane is used as the calculation lower surface of each area, which is not only in line with the actual construction process, but also can obviously reduce the error . The Fig. 6 is the cutting plane simplified model for area 4 . The design lower surface of area 4 can be simplified as the blue line shown in the Fig.6 (This simplified model can be summarized by comparing the distribution of the area 4's design elevation on the design drawing architectural and taking the Mode of the area 4's design elevation as the computing elevation for the upper and lower segment in the simplified model). To simplify the calculation, the red line is used as the calculating bottom elevation. As long as the shadow area up the red line equals to the area below, it can not only realize the balance of the overall earthwork volume, but also meet the requirements for most of the design bottom elevation in the area 4 .As shown in the equation 1 , the design bottom elevation $=804+x=$ $815.3 \mathrm{~m}$.

$0.5 \times\left(x^{2} \div 1.5\right) \times l=0.5 \times\left[(1.5-x)^{2} \div 1.5\right] \times l+3 l \times(1.5-x)$ 


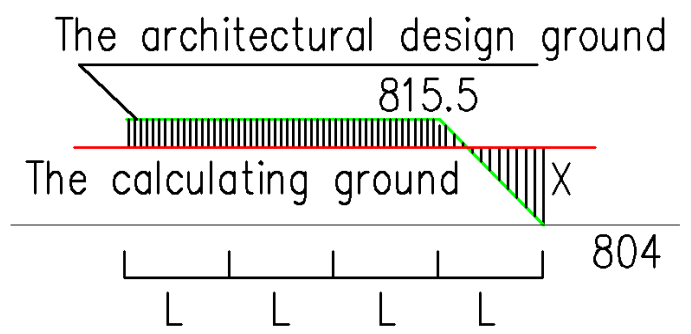

Fig.6 the simplified calculation model for area 4

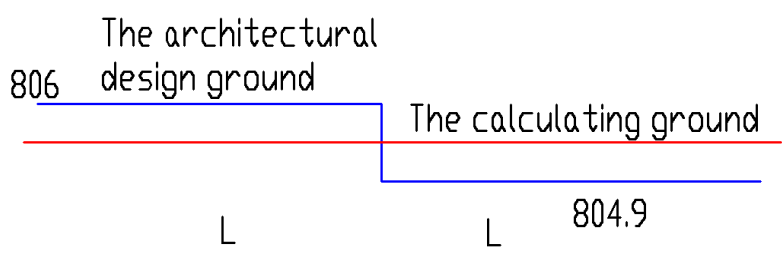

Fig.7 the simplified calculation model for area 3

In this way, the calculation elevation can be obtained in turns. Various area's simplified calculation model can be obtained by observing the design topography of each area. The area 5's model is similar to the area 4's. And the model of 1,2,3 is approximately same as the Fig.7.

Calculating bottom elevation can be summarized by the calculation model for each area, as shown in the table $1^{[1]}$. But for the actual project cases, the distribution of the building ground elevation for each area should be considered to avoid repeating to dig and fill the earthwork, delaying the construction period. Therefore, each calculation bottom elevation should also be close to the design bottom elevation of the large buildings in each area. So the final calculation bottom elevation is shown in the following table $2^{[4]}$.

Table 1 Calculating bottom elevation summary table

\begin{tabular}{|c|c|c|c|}
\hline \multirow{2}{*}{ Area highest } & $\begin{array}{l}\text { The lowest } \\
\text { design } \\
\text { elevation } / \mathrm{m}\end{array}$ & $\begin{array}{l}\text { The } \\
\text { design } \\
\text { elevation } / \mathrm{m}\end{array}$ & $\begin{array}{l}\text { Calculating } \\
\text { elevation/m }\end{array}$ \\
\hline 1 & 801.6 & 801 & 801.3 \\
\hline 2 & 806 & 804.9 & 805.4 \\
\hline 3 & 812 & 808.2 & 810.1 \\
\hline 4 & 815.5 & 814 & 815.3 \\
\hline 5 & 812.5 & 809 & 811.9 \\
\hline
\end{tabular}

Table 2 The final calculating bottom elevation summary table

\begin{tabular}{|r|c|}
\hline Area & $\begin{array}{c}\text { The final calculating bottom } \\
\text { elevation/m }\end{array}$ \\
\hline 1 & 801 \\
\hline 2 & 805 \\
\hline 3 & 809.5 \\
\hline 4 & 815.3 \\
\hline 5 & 811.5 \\
\hline
\end{tabular}




\section{Calculating the earthwork volume by the Southern CASS9.1 software}

In this case, the DTM method of the Southern CASS9.1 software is adopted to calculate the earthwork volume of the measurement area and the boundary sampling interval is taken as 2 meters . And the specific operation follows as: On the basis of the original field topographic map, the measurement area is divided up into five parts by the polyline. And then each part is selected in turn to generate the corresponding data file, named as the area 1(2,3,4,5).dat. By Choosing the DTM method earthwork calculation in the engineering application and the corresponding data file of each area, inputting the corresponding flat field elevation(the final calculating bottom elevation), selecting the boundary sampling interval as 2 meters, the digging and filling earthwork volume of each area is summarized in the table 3 at last.

Table 3 the summary table for each area's earthwork volume situ
\begin{tabular}{|c|r|r|r|}
\hline Area & $\begin{array}{c}\text { Flat field } \\
\text { elevation } / m\end{array}$ & $\begin{array}{c}\text { Amount of } \\
\text { cut } / m^{3}\end{array}$ & $\begin{array}{c}\text { Amount } ~ \\
\text { fill } / m^{3}\end{array}$ \\
\hline 1 & 801 & 12 & 9207 \\
\hline 2 & 805 & 2658 & 20204 \\
\hline 3 & 809.5 & 4918 & 8626 \\
\hline 4 & 815.3 & 1264 & 4502 \\
\hline 5 & 811.5 & 7765 & 345 \\
\hline
\end{tabular}

Table 4 the summary table for the earthwork volume situation of all the measurement area

\begin{tabular}{|c|c|c|c|}
\hline & $\begin{array}{c}\text { Amount of } \\
\text { cut } / m^{3}\end{array}$ & $\begin{array}{c}\text { Amount of } \\
\text { fill } / m^{3}\end{array}$ & $\begin{array}{c}\text { Earthwork } \\
\text { volume after } \\
\text { balance } / m^{3}\end{array}$ \\
\hline $\begin{array}{c}\text { Earthwork } \\
\text { volume/ } \\
m^{3}\end{array}$ & -16617 & 42884 & 26267 \\
\hline
\end{tabular}

Statistics of all the measurement area's earthwork volume situation is shown in table 4. And this conclusion meets the earthwork range given by the development and design side of the project.

\section{Conclusion}

When the designing lower surface is relatively complicated, distributing in a certain characteristics way, it will be time-consuming and laborsome to describe the designing bottom surface completely and accurately. However, the actual project needs to be done as fast as possible. At this time, the method of the paper is more practical and feasible, thus it is extremely worth of being generalized. If the project has a higher accuracy requirement, the segmented region can be further subdivided to describe the designing bottom surface more accurately. However, on the premise of guaranteeing the efficiency, it will be the best solution that a more accurate description to the designing surface can be done. Therefore, this method needs to be improved.

\section{Acknowledgements}

This work was financially supported by The key discipline of disaster prevention and reduction engineering and protective engineering.. 


\section{References}

[1] Guoqiang Feng, Liang Leng. Research on Selections of Elevation Points Nearby Work-areas for Earthwork Calculation based on DTM [J]. Geomatics \& Spatial Information Technology, 2014(8).

[2] Qiongying Feng, Analysis and Comparison of Earthwork Calculations Method with CASS7.0[J]. Geospatial Information, 2014(12).

[3] JianYing Liu, Methods of Calculating Earthwork by using CASS Software \& How to Calculate in Special Environment [J]. Urban Geotechnical Investigation \& Surveying, 2008.

[4] Zhu'an Chen, Yiyong Luo, Liting Zhang. Precision analysis and earthwork computation of land consolidation based on surfer[J]. Geotechnical Investigation \& Surveying, 2010,05: 53-56.

[5] Xiansen Liu, Jiwu Gan, Tieshan Wang. DTM Construction with CASS Digital Mapping Software[J]. Geomatics \& Spatial Information Technology,2010,33(4): 218-220.

[6] Š. Sokol - M. Lipták - M. Bajtala, Effects of density of input data for accuracy of volumes using DTM. In Geodesy and Mine surveying 2013: XX. Conference Company mine surveyor and geologists. Milín, ČR, 2. - 4.10.2013. Ostrava: TU Ostrava, 2013, s. 188-195. ISBN 978-80-2483190-9. 